\title{
Conversation Attentiveness and Following in 12- and 18-Week-Old Infants*
}

\author{
THOMAS M. HORNER AND LEIGH CHETHIK \\ The University of Michigan
}

\begin{abstract}
In recent years, the investigation of social transactional factors in early language and prelinguistic development have played an important role in reshaping concepts of communication and its ontogenesis. The present study reports findings concerning young infants' dispositions to follow the conversational interchanges of spontaneous adult dialogues. Two of 1312 -week-old intants (15\%) and 8 of 12 18 -week-old infants $(67 \%)$ showed organized shifts in visual attentiveness that were co-incident with shifts in speaking that occurred between adult speakers. Conversation monitoring of this sort went on in some instances for as long as 2 to $3 \mathrm{~min}$. The data are discussed from the standpoints of cognition-attention, affect, and subjectivity.
\end{abstract}

conversation monitoring communication

prelinguistic patterns affect attention

Considerable evidence has accrued over the past two decades which establishes the human infant early on as an authentic partner in social relationships (e.g., Ciba Foundation, 1975; Lewis \& Rosenblum, 1974; Schaffer, 1977; Tronick, 1982). The active nature of infants has been the basis of several approaches to prelinguistic development emphasizing inherent "conversational modes" in infant-mother transactions (e.g., Dore, 1979; Snow, 1977). The shared experience of communication is instrumental to the infant's eventual capacities for joint-referencing (with the mother) of objects and places (Butterworth \& Cochran, 1980; Scaife \& Bruner, 1975), for following interactive rule structures (Newson, 1979; Ratner \& Bruner, 1978), and for using the affective expressions of the mother to make simple but important judgments in ambiguous situations (Klinnert, Campos, Sorce, Emde, \& Svejda, 1983).

In the context of studies of face-to-face interactive dynamics in infancy, the investigators observed the phenomenon of 12- and 18-week-old infants selectively monitoring the ongoing conversations of nearby adults (mother and interviewer). The present study is a formal investigation of the phenomenon mounted in order to determine if 12- to 18-week-old infants systematically attend to the natural alternations of speaking in spontaneous adult-adult conversations. The data to be presented suggest both that periods of systematic

- The authors gratefully acknowledge the assistance of Pamela Raisman, Andrea Goodman, Janet Shapiro, and Jon Falk in the collection and coding of data reported in this paper.

Correspondence and requests for reprints should be sent to Thomas M. Horner, Infant Research Laboratory, Children's Psychiatric Hospital, University of Michigan Medical Center, Ann Arbor, MI 48109. 
conversation monitoring by infants occur, and that there is an increase in the frequency of its occurrence between 12 and 18 weeks. The data suggest that in addition to its developmental readiness to engage in direct interactive partnerships, the 12- to 18-week-old infant shows a capacity to attend selectively in the ongoing interactions (conversations) of others.

\section{METHOD}

\section{Subjects}

Thirteen 12-week-old ( 7 boys, 6 girls) and 12 18-week-old (10 boys, 2 girls) babies were seen in the Infant Research Laboratory on two occasions 2-3 days apart. All of the babies were full term. Subjects had been recruited prenatally through contacts with parents at local LaMaze birth preparation film showings. All of the babies were living in maritally intact circumstances and were physically in good health. The educational levels of the mothers and fathers for the entire sample ranged from high school graduate to advanced graduate and professional degrees.

\section{Procedures}

Each of the two visits to the laboratory was conducted in the same manner. The mother and baby were initially acclimated to the laboratory setting while the procedures to be used were explained. Infants sat on their mothers' laps during the introductory phase. During the actual observation procedure, infants sat in an infant seat adjusted to an angle of $45^{\circ}$. (Infants who did not tolerate this arrangement were not included.) Mothers sat directly opposite, face-to-face, in a fashion typically used in social interaction studies of infants (e.g., Als, Tronick, \& Brazelton, 1979; Field, 1977; Stern, 1974).

The observational procedure consisted of two phases: interviewer absent/ interviewer present, each of which was further subdivided. During the first phase (observer absent), the mother was instructed to interact with the baby, she "taking the lead" (Mother Leads condition). When a bell sounded ( $3 \mathrm{~min}$ later), she was to fill out a brief questionnaire, thereby initiating a Silent Distraction condition. When this was complete (about $21 / 2-3$ min later), she was to resume interacting with the baby, this time letting the baby "take the lead" (Baby Leads condition).

Three minutes later the observer re-entered the room to begin the second phase. The second phase provided the observational data that were analyzed for the present study. Following re-entrance, the observer sat and conversed with the mother for about 3-4 min (Social Distraction condition). The aim of this condition, as well as of the Silent Distraction condition, was to distract the mother naturally in order to study the infant's attention and social initiatives toward her (Horner \& Carlson, 1985). The observation procedures concluded with a brief period of observer-infant face-to-face interaction. 


\section{Data Recording}

Data were recorded using split-screen videotaping devices with digital time display.

This study focuses on the Social Distraction condition. Two taped segments were produced for each dyad, yielding a total of 26 episodes for 12-weekolds and 24 episodes for 18-week-olds. A second-by-second coding system was developed for tracking the visual attention of the infant throughout the length of the Social Distraction condition. For each second, the baby's visual attention was coded according to one of the following categories:

- Watching Mother:

- Orienting to Mother:

- Averted:

- Orienting to Interviewer:

- Watching Interviewer:
Gaze focused on mother: face/shoulder region. Gaze shifting from interviewer to mother.

Gaze focused away from either interviewer's or mother's face/shoulder region.

Gaze shifting from mother to interviewer.

Gaze focused on interviewer's face/shoulder region.

Each second was also coded for whether the mother, interviewer, both adults, or neither adult was speaking. In this way the infant's attention relative to the speaker's conversational activity could be graphically portrayed (see Figure 1).'

Intercoder exact agreements for parent speaking and interviewer speaking were .95 and .86 , respectively. Agreement coefficients are based on coders' independent ratings of several tapes. Coders were allowed to view each second of the segments as many times as necessary to achieve confidence in the category finally assigned. The chief obstacle to achieving higher percentages of agreement was a recurrent uncertainty about whether occasional vocalizations were those of the mother or the female interviewer. Coders were able to rate the two watching categories (watching mother, watching interviewer) and the avert category with high degrees of intercoder agreement: .90, .91, and .86 , respectively. Good percentages of agreement for orienting to mother and to the interviewer were more difficult to attain (.52 and .50 , respectively) despite a digital display of elapsed time, because it was frequently difficult to agree exactly when eye-to-eye contacts associated with infant gaze shift commenced or terminated.

After the videotapes were coded (see Figure 1), each record was examined independently by the investigators in order to classify segments of conversation-monitoring activity. Segments of conversation monitoring were defined

' Observers made multiple passes through the data to determine second-by-second ratings of attention or talking. The form presented in Figure 1 is a facsimile of the form used by coders. Two observers rated the protocols both for parent talking and for infant attention. For mechanical reasons, the video playback unit could not be stopped by 1 -s intervals. However, it was quite simple to determine talking/nontalking correspondences to the digitally displayed time on the tape. Similarly, it was quite simple to monitor the visual image of the infant's attention. This was verified when two individuals looked at segments of the tapes together. 

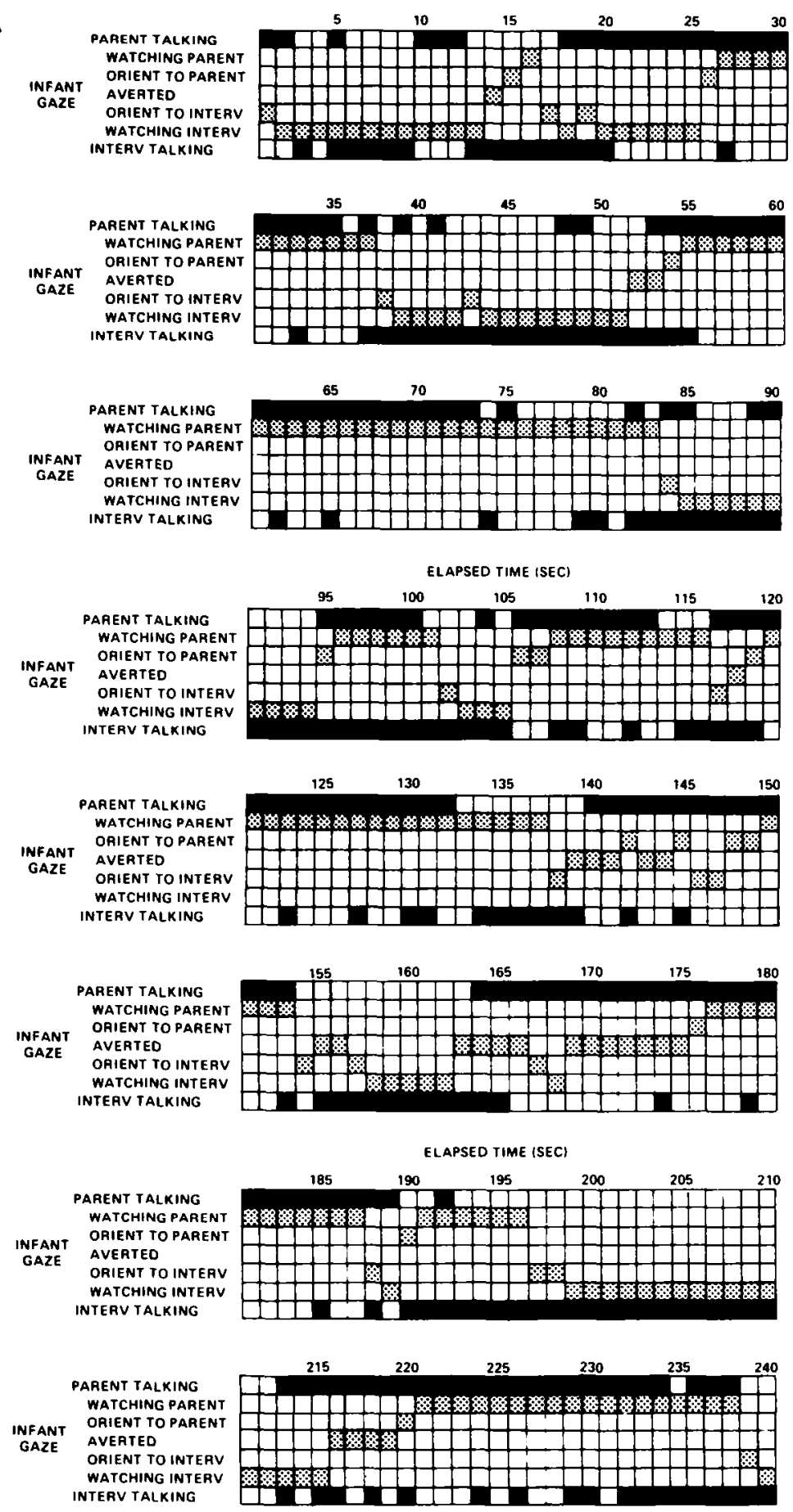

Figure 1. Protocol for the conversation monitoring behavior of a 12-week-old male. 
as instances where the infant's gaze activity was coordinated with the speakers' conversational activity such that two or more gaze shifts occurred proximal to corresponding shifts in adult speaking. In order to be considered proximal, the infant had to shift gaze from speaker to speaker within several seconds of the onset of the next speaker's talking. Certain exceptions applied: If Speaker A stopped, Speaker B started to speak, and then Speaker A resumed within a few seconds, the baby was not considered to have "missed" the shift if no shift occurred. If the infant missed one shift in what was otherwise an extended sequence of gaze shifts synchronous with conversational shifts, the entire segment was considered to be an example of extended conversation monitoring. If an infant looked away from a speaker for a few moments but resumed watching the speaker, this was not considered to be a break in the monitoring activity of the infant.

\section{RESULTS}

The following data are for extended segments of conversation monitoring (see Table 1). Two 12-week-olds (14.6\%) and eight 18-week-olds (66.7\%) displayed extended continuous segments of conversation monitoring. The mean length of the 12-week-olds' segments was $185 \mathrm{~s}$ (Range $=130-240 \mathrm{~s}$ ). The 10 infants who showed extended conversation monitoring supplied 16 examples of systematic coordinated attentional shifts proximal to adult conversational shifts. The number of actual attentional shifts per example ranged from 2 to 16 . Chisquares computed for these segments (Mother Talking, Interviewer Talking, Both Adults Talking; Infant Watching Mother, Infant Watching Interviewer, Infant's Attention Averted) were significant $(p \leq .001) .^{2}$ Only two did not achieve statistical significance.

The 4-min record of a 12-week-old infant (Subject 2 in Table 1) who displayed an extended period of conversation monitoring is presented in Figure 1. Conversation monitoring is particularly evident between seconds 26 and 137 and seconds 175 and 240 . The outer bars (dark) of the figure portray the backand-forth nature of the conversation. The brief segments of overlapped talking (e.g., at seconds 95-100 and seconds 232-238) are, when viewed on the videotaped record of this dyad, really segments of interspersed quips rather than simultaneous communications, and the single- and double-second marks generally refer to "uh-huhs" and other punctuating vocalizations. The inner bars depict the infant's changing visual attentiveness. The segment between seconds 135-175 constitutes a small interlude of averted interest (punctuated by moments of renewed interest at seconds 150-154 and 158-162), followed again by extended monitoring. During periods of overlapped (heavily interspersed) dialogue, the infant tended to attend to the mother's speaking activity.

\footnotetext{
${ }^{2}$ Since the frequency of the Orienting to Mother/Interviewer and Neither Adult Speaking categories was extremely small across subjects, these categories were not included in the statistical analyses.
} 


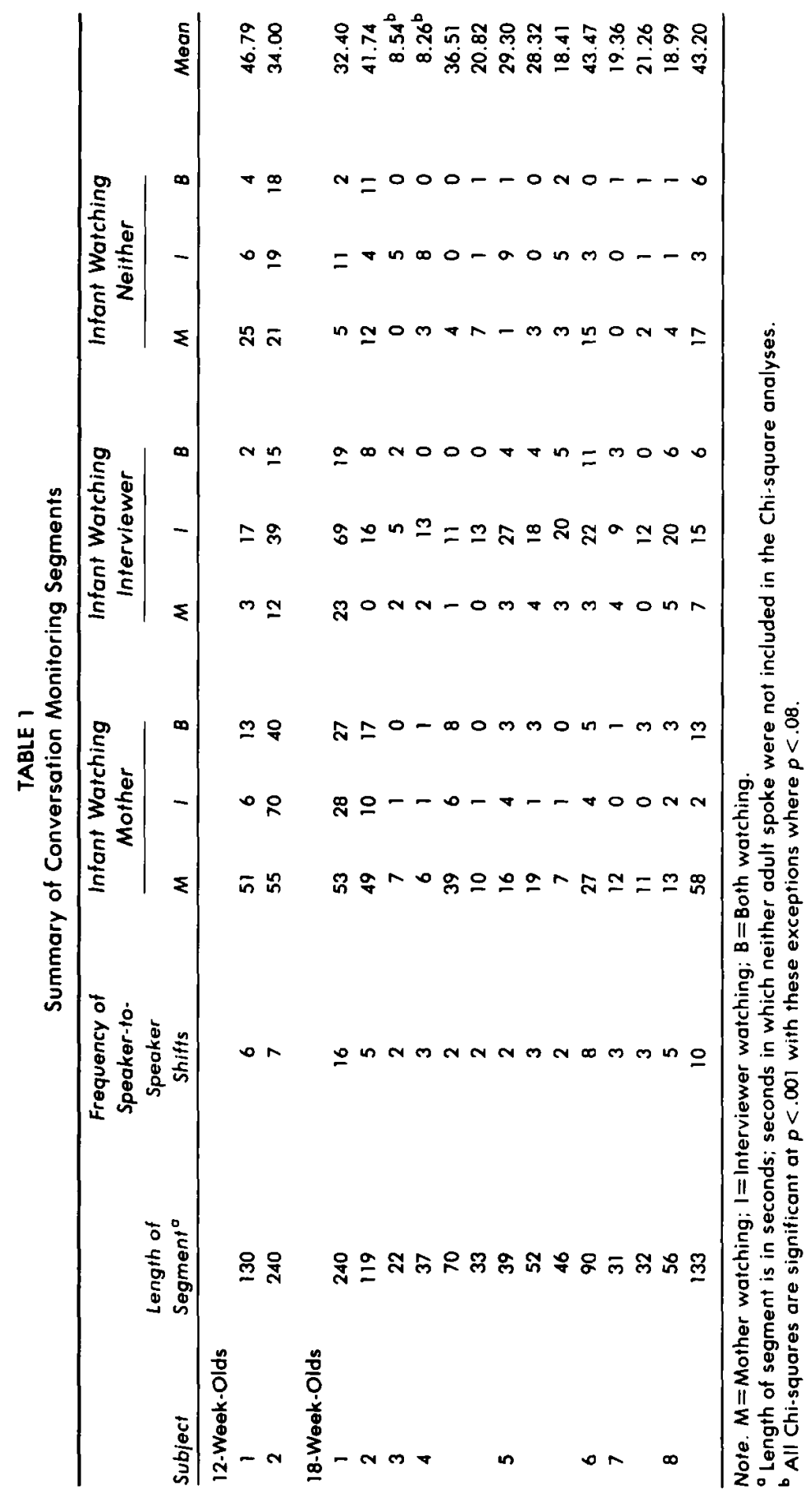




\section{DISCUSSION}

The data demonstrate the young infant's capacities for focused awareness of and active interest in the social interchanges of those in its vicinity. The differences in proportions of infants displaying conversation attentiveness at 12 and 18 weeks indicate a rapid increment that is consonant with other burgeoning capabilities in the 3-4 month period (for example, visually guided grasping, intermodal perceptual integrations, etc.).

Not all the infants in the study displayed the conversation-attentive behavior. This presentation focuses on those babies who demonstrated the most definite and most prolonged sequences of conversation-following behavior. Being aware of the performances of babies who exhibited such sequences, the investigators are more confident that many of the briefer segments that occurred amongst a larger number of infants in each age group were probably also instances of the same phenomenon rather than the random deployments of attention they sometimes seemed to be. Thus, the observed protracted phases of conversation following may be unique solely for their duration and organization, not for their conversation-attentive significance per se. Most babies are from time to time attentive to the social interactions of adults, some even to a large extent. But not all babies are inclined to display this type of attentiveness (at least not under the present circumscribed conditions), and not all of the babies who display it do so in a sustained fashion. The behaviors of the babies reported here, then, reflect what is probably a more broadly distributed capacity.

\section{Cognition-Attention}

The 6- to 12-week-old infant is often viewed as being at an important crossing point in development, particularly with respect to the expression and regulation of affect and the emergence of sociability (Stern, 1974). Central to this is the important transition from externally augmented state regulation to more intrinsically based state regulation (Emde \& Robinson, 1979). With physical support of its head, the infant is able early on to look around and "take in the sights," so to speak (see Charlesworth, 1966). With the increased head and neck control acquired by $12-18$ weeks, the infant has the voluntary motoric capacities to pursue its interests.

In a case study of the early development of socially embedded attention in an infant between 11-17 weeks (Horner, 1985), the complex attentionalbehavioral capacities of this period were illustrated. These capacities entail voluntary behavioral devices that engage the mother and absorb her interest. They are not as obligatory in character as once described (Stechler \& Latz, 1966). Studies in the past decade have made it evident that from birth onward, the infant is capable of active perceptual routines geared toward constructing mental representations out of basic information contained in the stimulus (e.g., Haith, 1977). During the 12- to 18-week period, cross-modal perceptual-motor 
activity emerges, leading eventually to what Piaget and others have taken to be quasi-intentional capacities (Greenfield, 1980; Piaget, 1952). Use of the term "voluntary" (above) is indeed meant to convey not only the specific neuromotor properties of many attention-deployment acts in the 12-to 18-week-old infant, but also their quasi-intentional properties as well. The extended episodes of conversation monitoring that have been depicted are strongly suggestive of voluntary attentional capacities that entail sustained watching and listening punctuated at the right time by focused attentional shifts.

\section{Affect}

There has been considerable theoretical and empirical concern over the past decade with affective phenomena in infancy. At the forefront have been attempts to bring objective-quantifiable methods to bear on the affective expressions of very young infants (Gaensbauer \& Harmon, 1981). Such methods are based on cross-cultural and other empirical studies of universal patterns of discrete affective expression as established by Ekman, Friesen, and Ellsworth (1972), Izard (1977), and others.

Conspicuous amongst the array of discrete affective states that have been identified is that of interest. Interest has discernible affect associated with it, affect which "focuses and sustains attention, information processing and exploratory activity"' (Langsdorf, Izard, Rayias, \& Hembree, 1983, p. 375). The face of the interested infant is unambiguous with respect to its underlying affect, whereas the face of the infant who is simply monitoring a situation may be ambiguous with respect to underlying affect. Throughout all of the videotaped examples of extended conversation following that have been collected by the present investigators, there are sustained expressions of focused interest on the parts of depicted babies, interest which frequently has an appearance that could be accurately described as "absorbed." Thus, although affect was not specifically coded in this study, it was evident throughout that interest is a major affective correlate of the conversation-monitoring behavior that has been described.

\section{Subjectivity}

What are the babies who monitor the conversations of nearby adults experiencing? This is a matter of subjective content which extends too far beyond the data to merit extensive speculation. Recent reports have estimated the amount of variance accounting for 2 -year-old language competence by direct childadult conversation to be about equal to the amount of variance accounting for it by time spent watching parents converse (Lewis, 1982). Perhaps experiences of the latter type begin to occur quite early in infancy, well before linguistic competence is underway. Conversation following may be an important component, then, of prelinguistic experience and capabilities.

There are also important reports of social referencing in 12-month-old infants (Klinnert et al., 1983). It is not untenable that these somewhat sophisti- 
cated channels of information processing and situation assessment with respect to others' facial expressions have early roots in the specific types of interests and social-stimulus tracking capabilities that are depicted by the data presented here. The later emergence of empathic behavior (see, e.g., Hoffman, 1978) may also be developmentally linked to the early phenomenon of conversation monitoring. Finally, conversation monitoring may be part of an organized core of subjective experience of the kind recently delineated by Stern (1985).

\section{Validity of the Data}

Are the babies depicted in this study precocious in their development, manifesting traits that are not generalizable across the normative span of their agemates? Statistical analyses suggest not. It will be important to address this question systematically in future studies of infants of similar socioeconomic status, comparing, for example, the linguistic competence at subsequent points in development of infants who do and do not display conversation-monitoring behavior early in infancy. Such longitudinal studies should give careful attention to maximizing the infant's opportunity to display capacities and interests related to conversation monitoring, considering, for example, larger or more numerous segments of maternal social distraction, alternative paradigms for eliciting the target phenomenon (e.g., maternal holding; mother and father conversing), and experimental manipulations of the actual verbal activity of the mother and interviewer.

Are the babies whose conversation-monitoring behaviors have been depicted simply "checking the stranger out" and not actually attending to the organizational properties of the conversing dyad? Here more confident assertions can be made. There is a strong suggestion throughout all of the videotapes that the noise and activity associated with the interviewer's entrance into the laboratory to converse with the mother initially drew the infant's attention to him or her; this is consistent with patterns of stranger interest that are frequently evident at 12-18 weeks of age (Horner, 1980) - an age commonly associated with positive and tractable reactions to the presence of unfamiliar, friendly adults. Yet present data strongly suggest that in each of the instances of extended conversation monitoring, and in many other briefer instances of the same phenomenon, the manner of watching adult-adult interchanges was not one of "checking," but one of active and systematic monitoring.

\section{REFERENCES}

Als, H., Tronick, E., \& Brazelton, T.B. (1979). Analysis of face-to-face infant-adult dyads. In M. Lamb, S.J. Suomi, \& G.S. Stephenson (Eds.), Social interaction analysis. Madison, WI: University of Wisconsin Press.

Butterworth, G.E., \& Cochran, E. (1980). Towards a mechanism of joint visual attention in human infancy. International Journal of Behavioral Development, 3, 253-272.

Charlesworth, W.R. (1966). Persistence of orienting and attending behavior in infarts as a function of stimulus-locus uncertainty. Child Development, 37, 473-491. 
Ciba Foundation. (1975). Parent-infant interaction. New York: Associated Scientific Publishers.

Dore, J. (1979). Conversation and preschool language development. In P. Fletcher \& M. Garman (Eds.), Language acquisition. Cambridge, England: Cambridge University Press.

Ekman, P., Friesen, W.V., \& Ellsworth, P.C. (1972). Emotion in the human face. New York: Pergamon.

Emde, R.N., \& Robinson, J. (1979). The first two months: Recent research in development of psychobiology and the changing view of the newborn. In J.D. Call, J.D. Noshpitz, R.I. Cohen, \& I.N. Berlin (Eds.), The basic handbook of child psychiatry: Vol. I. Development. New York: Basic.

Field, T. (1977). Effects of early separation, interactive deficits, and experimental manipulations on infant-mother face-to-face interaction. Child Development, 48, 763-771.

Gaensbauer, T.J., \& Harmon, R.J. (1981). Clinical assessment in infancy using structured playroom situations. Journal of the American Academy of Child Psychiatry, 20, 264-280.

Greenfield, P.M. (1980). Toward an operational and logical analysis of intentionality: The use of discourse in early child language. In D.R. Olson (Ed.), The social foundations of language and thought. New York: Norton.

Haith, M.M. (1977). Rules that infants look by. Hillsdale, NJ: Erlbaum.

Hoffman, M.L. (1978). Empathy, its development and prosocial implication. Nebraska symposium on motivation. Lincoln, NE: University of Nebraska Press.

Horner, T.M. (1980). Two methods of studying stranger reactivity in infant: A review. Journal of Child Psychology and Psychiatry, 21, 203-219.

Horner, T.M. (1985). Subjectivity, intentionality, and the emergence of reality testing in early infancy. Psychoanalytic Psychology, 2, 341-363.

Horner, T.M., \& Carlson, G. (1985, October). Social initiatives by 12- to 18-week-old infants during periods of maternal distraction. Paper presented at the meeting of the American Academy of Child Psychiatry, San Antonio, TX.

Izard, C. (1977). Human emotions. New York: Plenum.

Klinnert, M., Campos, J.J., Sorce, J.F., Emde, R.N., \& Svejda, M. (1983). Emotions as behavior regulators: Social referencing in infancy. In R. Plutchik \& H. Kellerman (Eds.), Emotion: Theory, research, and experience. New York: Academic.

Langsdorf, P., Izard, C.E., Rayias, M., \& Hembree, E.A. (1983). Interest expression, visual fixation, and heart-rate changes in 2- to 8-month-old infants. Developmental Psychology, 19, 375-386.

Lewis, M. (1982, March). The family as a social system: The effects of the infant on the caregiving environment. Institute given at the 6th Annual Conference of the Michigan Association of Infant Mental Health, Ann Arbor, MI.

Lewis, M., \& Rosenblum, L.A. (Eds.). (1974). The effect of the infant on its caregiver. New York: Wiley.

Newson, J. (1979). The growth of shared understandings between infant and caregiver. In M. Bullowa (Ed.), Before speech. Cambridge, England: Cambridge University Press.

Piaget, J. (1952). The origins of intelligence in children. New York: International Universities Press.

Ratner, N., \& Bruner, J.S. (1978). Games, social exchange and the acquisition of language. Journal of Child Language, 5, 391-401.

Scaife, M., \& Bruner, J.S. (1975). The capacity for joint visual attention in the infant. Nature, $253,265-266$.

Schaffer, H.R. (Ed.). (1977). Studies of mother-infant interaction. New York: Academic.

Snow, C. (1977). The development of conversation between mothers and babies. Journal of Child Language, 4, 1-22.

Stechler, G., \& Latz, E. (1966). Some observations on attention and arousal in the human infant. Journal of the American Academy of Child Psychiatry, 5, 517-525. 
Stern, D. (1974). Mother and infant at play: The dyadic interaction involving facial, vocal, and gaze behaviors. In M. Lewis \& L.A. Rosenblum (Eds.), The effect of the infant on its caregiver. New York: Wiley.

Stern, D. (1985). The interpersonal world of the infant. New York: Basic.

Tronick. E.F. (Ed.). (1982). Social interchange in infancy. Affect, cognition and communication. Baltimore: University Park Press.

29 January 1985; Revised 16 January 1986 